\title{
Multi-Residue Determination of Pesticides in Vegetables by Gas Chromatography/Ion Trap Mass Spectrometry
}

\author{
C.-J. Tao $\cdot$ J.-Y. Hu $\cdot$ J.-Z. Li $\cdot$ S.-S. Zheng $\cdot$ \\ W. Liu $\cdot$ C.-J. Li
}

Received: 28 January 2008/Accepted: 22 August 2008/Published online: 16 September 2008

(C) Springer Science+Business Media, LLC 2008

\begin{abstract}
To monitor possible contamination of edible vegetables by common pesticides, an analytical method using gas chromatography combined with ion trap spectrometry (GC-IT/MS) was developed to measure simultaneously up to 39 pesticide residues, belonging to organophosphors, organochlorines, pyrethroids or carbamates classes, left on four kinds of popular vegetables. The procedure entails addition of acetone, dichloromethane, and sodium chloride to a small amount of vegetable, then the mixture was shaken intensively and centrifuged for phase separation. An aliquot of the organic layer was cleanup using solid-phase extraction (SPE) cartridges filled with graphitized carbon black (GCB) in combination with acidic aluminum oxide. Gas chromatography with ion trap mass spectrometer was then used for qualitative and quantitative determination of the pesticides. The GCB combination with acidic aluminum oxide was found more suitable than florisil, aluminum oxide and silicon dioxide for sample cleanup with recoveries above $70 \%$ for most
\end{abstract}

\section{C.-J. Tao}

Institute for the Control of Agrochemicals,

Ministry of Agriculture, Beijing 100026, China

C.-J. Tao · J.-Y. Hu (ه) - J.-Z. Li

Research Center for Eco-Environmental Sciences, Chinese Academy of Sciences, Beijing 100085, China

e-mail: jihyehu@sas.ustb.edu.cn; hujiye@ rcees.ac.cn

J.-Y. Hu

School of Applied Science, University of Science and Technology Beijing, Beijing 10083, China

S.-S. Zheng · W. Liu - C.-J. Li

Department of Applied Chemistry, China Agricultural

University, Beijing 100094, China pesticides in removing the majority of co-extracted matrices. Variation coefficients of the repeatability typically smaller than $20 \%$ have been achieved for a wide range of the investigated pesticides. A set of critical instrument parameters for the GC-IT/MS Varian system in the MS mode was established. Based on optimization work conducted in this study, the 39 pesticides were separated successively with the limits of detection between 0.02 and $0.1 \mathrm{mg} / \mathrm{kg}$.

Keywords Multi-residue pesticide analysis · Vegetables . Gas chromatography with ion trap spectrometry (GC-IT/ MS)

Great productivity gains can be achieved in agriculture, by using the adequate pesticides. Indeed, they are needed to meet the world's demand on foodstuffs and no other alternative can compete to be used in such a large scale. As a result, consumers are exposed to pesticides, usually in minute quantities, in several food groups including crops, fruits and vegetables and so on. The preservation of human health from exposure to pesticide residues in foodstuffs remains a major objective in China.

Pesticides constitute a very important group of chemical compounds that have to be controlled due to their high toxicity and their widespread use in agricultural practice for field and post-harvest protection. As a consequence, governments and international organization have established maximum residue limits (MRLs) in food to ensure that they are not present at levels that may pose a health risk to the public (Albero et al. 2005).

Developing faster, more cost-effective and environmentfriendly procedures of multi-residue analytical methods for simultaneous determination them is very important to 
monitor the pesticide residues in food. Classic method for extraction and purifying pesticide residues in fruits and vegetable is often a time-consuming, labour-intensive, and expensive process due to the complexity of the many analytes and matrices involved. The procedures include liquidliquid extraction (LLE), solid-phase extraction (SPE), accelerated solvent extraction (ASE), gel permeation chromatography (GPC), microwave-assisted extraction (MAE), matrix solid-phase dispersion (MSPE) and supercritical fluid extraction (SFE) (Fenoll et al. 2007). A large variety of chromatographic methods have been used for the final determination of the pesticide residues in food. Gas chromatography with different selective detectors as electron-capture (ECD), nitrogen-phosphorus (NPD), and flame photometry (FPD) was used. Liquid chromatograph (LC) with diode-array and fluorescence detection was effective in thermally labile and nonvolatile compounds determination (Albero et al. 2004). But in combination with mass spectral detection chromatographic methods are still the first choice for many applications, by reason of their flexibility, selectivity, wide analytical scope, qualitative and quantitative utility and sensitivity (Fillion et al. 1995, 2000; Lee et al. 1991; Liao et al. 1991).

To our knowledge, little reference is available on the multi-residue analysis using GC-IT/MS concerning 39 pesticides in our selected vegetables. The principal aim of this work was to develop a rapid-multi-residue method for the simultaneous analysis of 39 pesticides in four kinds of vegetables (cucumber, cabbage, cole and capsicum) most widely consumed in China. The paper describes an extraction, using a low volume of organic solvent and SPE cleanup procedure as an alterative to liquid-liquid partition. The residues in selected four kinds of vegetables were final determined and confirmed by GC-IT/MS. GC with IT/ MS detection provides high confidence in identification of target analytes, based on a selected parent ion and a whole mass spectrum of its daughter ions, high sensitivity and selectivity, as well as low cost and easy in operation and maintenance. These characteristics have made GC-MS analysis by ion-trap system a very competitive and widely used technique.

\section{Materials and Methods}

Pesticides standards were obtained from Ministry of Agricultural of the People's Republic of China, and all compounds were of $99 \%$ purity. Table 1 lists the 39 pesticides. Acetone, dichloromethane, methanol and $n$-hexane, of residue analysis grade, were purchased from Dikma Limited (China). Anhydrous sodium sulfate and sodium chloride in power form and analytical grade were also obtained from Dikma Limited (China). The solid-phase
Table 1 Chromatographic and mass spectral data obtained by the GC-MS methods of all tested pesticides as well as selected ions for quantification and qualification

\begin{tabular}{|c|c|c|c|c|}
\hline Pesticide & $\mathrm{M}_{\mathrm{R}}$ & $\begin{array}{l}\text { Retention } \\
\text { time (min) }\end{array}$ & $\begin{array}{l}\text { Target } \\
\text { ion }(\mathrm{m} / \mathrm{z})\end{array}$ & $\begin{array}{l}\text { Qualifier } \\
\text { ion }(\mathrm{m} / \mathrm{z})\end{array}$ \\
\hline$\alpha-\mathrm{BHC}$ & 288 & 21.662 & 219 & $109,183,219$ \\
\hline$\beta$-BHC & 288 & 22.462 & 219 & $109,183,219$ \\
\hline$\gamma$-BHC & 288 & 23.452 & 219 & $109,183,219$ \\
\hline$\delta$-BHC & 288 & 23.823 & 219 & $109,183,219$ \\
\hline $\mathrm{O}, \mathrm{P}^{\prime}-\mathrm{DDT}$ & 352 & 34.913 & 235 & $165,199,235,352$ \\
\hline $\mathrm{P}, \mathrm{P}^{\prime}-\mathrm{DDT}$ & 352 & 35.704 & 235 & $165,199,235,352$ \\
\hline $\mathrm{P}, \mathrm{P}^{\prime}$-DDE & 316 & 33.745 & 318 & $176,206,318$ \\
\hline $\mathrm{P}, \mathrm{P}^{\prime}-\mathrm{DDD}$ & 318 & 34.672 & 235 & $165,199,235$ \\
\hline$\alpha$-Endosulfan & 404 & 33.243 & 339 & $205,267,339$ \\
\hline$\beta$-Endosulfan & 404 & 34.513 & 339 & $165,199,235$ \\
\hline Dichlorvos & 220 & 10.453 & 109 & $109,185,221$ \\
\hline Methamidophos & 141 & 9.904 & 94 & $94,141,142$ \\
\hline Omethoate & 213 & 17.851 & 156 & $110,156,214$ \\
\hline Monocrotophos & 223 & 20.034 & 127 & $67,127,192$ \\
\hline Phorate & 260 & 21.323 & 260 & $121,231,260$ \\
\hline Dimethoate & 229 & 21.792 & 230 & $87,212,230$ \\
\hline Phosphamidon & 299 & 26.268 & 264 & $127,264,300$ \\
\hline Diazinon & 304 & 24.333 & 304 & $137,179,304$ \\
\hline $\begin{array}{l}\text { Parathion- } \\
\text { methyl }\end{array}$ & 263 & 26.973 & 263 & 247,263 \\
\hline Fenitrothion & 277 & 28.604 & 277 & $125,260,277$ \\
\hline Fenthion & 278 & 29.803 & 278 & 125,278 \\
\hline Parathion & 291 & 30.013 & 291 & $109,275,291$ \\
\hline Chlorpyrifos & 349 & 30.083 & 314 & $286,314,352$ \\
\hline Phosfolan & 255 & 30.953 & 168 & $92,168,255$ \\
\hline $\begin{array}{l}\text { Isofenfos- } \\
\text { methyl }\end{array}$ & 317 & 34.484 & 199 & $121,199,231,273$ \\
\hline Methidathion & 302 & 32.522 & 145 & $85,125,145$ \\
\hline Profenofos & 372 & 33.482 & 339 & $297,339,375$ \\
\hline Triasophos & 313 & 34.742 & 257 & $161,257,314$ \\
\hline Optunal & 288 & 30.174 & 136 & $136,231,289$ \\
\hline Methomyl & 162 & 7.641 & 105 & $88,105,106$ \\
\hline Isoprocarb & 193 & 16.854 & 121 & $121,136,194$ \\
\hline Propuxur & 207 & 18.704 & 110 & $110,152,210$ \\
\hline BPMC & 209 & 18.782 & 121 & $121,150,208$ \\
\hline Carbofuran & 221 & 22.092 & 164 & 164,222 \\
\hline Pirimicarb & 238 & 25.603 & 166 & 166,239 \\
\hline $\begin{array}{l}\text { 3-OH } \\
\quad \text { carbofuran }\end{array}$ & 237 & 26.393 & 180 & $137,180,220$ \\
\hline$\beta$-Cypermethrin & 416 & 42.443 & 163 & $91,163,181,208$ \\
\hline Fenvalerate & 419 & $44.692 / 45.414$ & 125 & $125,167,225$ \\
\hline Deltamethrin & 502 & 47.514 & 253 & $172,181,253$ \\
\hline
\end{tabular}

extraction sorbents as florisil, graphitized carbon black (GCB), acidic aluminum oxide, and silicon dioxide in power form with a particle size of $40 \mu \mathrm{m}$ were obtained from Dikma Limited (China). The selected vegetables were 
Table 2 Mean recoveries (\%) at three fortified levels and LODs for pesticides determined by the multi-residue method

\begin{tabular}{|c|c|c|c|c|c|c|c|c|c|}
\hline Compound & Cucumber & $\mathrm{CV}(\%)$ & Cabbage & CV (\%) & Cole & $\mathrm{CV}(\%)$ & Capsicum & $\mathrm{CV}(\%)$ & $\mathrm{LOD}(\mathrm{mg} / \mathrm{kg})$ \\
\hline$\alpha-\mathrm{BHC}$ & 91.5 & 3.61 & 77.4 & 4.49 & 99.9 & 13.3 & 80.4 & 9.6 & 0.05 \\
\hline$\beta$-BHC & 82.1 & 6.16 & 85.4 & 19.88 & 93.9 & 4.3 & 76.6 & 7.9 & 0.03 \\
\hline$\gamma$-BHC & 91.0 & 6.66 & 81.5 & 3.31 & 89.1 & 5.1 & 79.9 & 5.1 & 0.03 \\
\hline$\delta$-BHC & 92.7 & 7.74 & 84.9 & 12.77 & 91.9 & 14.4 & 73.3 & 4.5 & 0.03 \\
\hline $\mathrm{O}, \mathrm{P}^{\prime}-\mathrm{DDT}$ & 96.8 & 7.5 & 88.5 & 19.09 & 120.8 & 4.4 & 75.7 & 19.2 & 0.03 \\
\hline $\mathrm{P}, \mathrm{P}^{\prime}$-DDT & 109.0 & 8.52 & 84.7 & 13.74 & 125.7 & 5.1 & 69.2 & 18.5 & 0.03 \\
\hline $\mathrm{P}, \mathrm{P}^{\prime}-\mathrm{DDE}$ & 91.9 & 5.18 & 94.0 & 13.17 & 118.5 & 18.9 & 82.8 & 4.3 & 0.04 \\
\hline $\mathrm{P}, \mathrm{P}^{\prime}-\mathrm{DDD}$ & 80.5 & 3.34 & 87.5 & 10.39 & 114.6 & 5.7 & 83.1 & 7.3 & 0.04 \\
\hline$\alpha$-Endosulfan & 82.0 & 0.19 & 89.4 & 7.89 & 112.8 & 16.2 & 70.0 & 7.9 & 0.03 \\
\hline$\beta$-Endosulfan & 93.7 & 9.93 & 80.4 & 10.02 & 82.5 & 9.3 & 78.6 & 14.5 & 0.05 \\
\hline Dichlorvos & 95.1 & 12.54 & 85.0 & 17.13 & 107.5 & 4.5 & 65.0 & 5.6 & 0.05 \\
\hline Methamidophos & 68.4 & 13.19 & 123.3 & 6.61 & 127.4 & 6.5 & 91.8 & 9.9 & 0.08 \\
\hline Omethoate & 66.5 & 10.72 & 124.3 & 12.32 & 136.1 & 7.0 & 83.5 & 8.5 & 0.1 \\
\hline Monocrotophos & 75.3 & 11.93 & 125.7 & 9.34 & 126.4 & 12.3 & 73.3 & 8.0 & 0.1 \\
\hline Phorate & 96.0 & 4.57 & 58.6 & 10.89 & 81.0 & 7.9 & 75.9 & 12.0 & 0.04 \\
\hline Dimethoate & 88.1 & 11.41 & 95.1 & 14.72 & 93.8 & 14.9 & 93.8 & 14.6 & 0.08 \\
\hline Phosphamidon & 86.0 & 6.45 & 98.6 & 2.31 & 124.7 & 11.3 & 92.3 & 10.0 & 0.1 \\
\hline Diazinon & 93.0 & 4.95 & 78.7 & 2.61 & 115.1 & 7.9 & 83.4 & 12.5 & 0.03 \\
\hline Parathion-methyl & 69.9 & 6.81 & 74.5 & 7.70 & 91.4 & 5.6 & 64.3 & 12.3 & 0.05 \\
\hline Fenitrothion & 76.8 & 7.24 & 81.7 & 3.50 & 96.2 & 9.9 & 73.7 & 9.5 & 0.04 \\
\hline Fenthion & 78.7 & 8.12 & 82.2 & 8.86 & 105.3 & 10. & 77.9 & 9.6 & 0.04 \\
\hline Parathion & 84.0 & 12.86 & 83.4 & 4.79 & 107.1 & 16.5 & 77.9 & 4.9 & 0.05 \\
\hline Chlorpyrifos & 74.2 & 9.60 & 76.7 & 5.05 & 94.0 & 37 & 67.0 & 8.9 & 0.03 \\
\hline Phosfolan & 64.0 & 4.46 & 120.1 & 10.83 & 120.4 & 7.1 & 85.2 & 3.3 & 0.1 \\
\hline Isofenfos-methyl & 86.2 & 6.34 & 80.6 & 10.30 & 105.1 & 9.3 & 92.0 & 9.0 & 0.02 \\
\hline Methidathion & 84.3 & 14.07 & 86.4 & 19.34 & 110.4 & 5.5 & 72.8 & 5.7 & 0.05 \\
\hline Profenofos & 80.5 & 14.28 & 74.5 & 13.91 & 89.1 & 8.4 & 72.5 & 9.9 & 0.05 \\
\hline Triasophos & 28.2 & 16.15 & 39.8 & 18.35 & 34.2 & 14.1 & 41.3 & 7.8 & 0.1 \\
\hline Optuanl & 86.5 & 14.51 & 84.2 & 4.18 & 100.5 & 8.1 & 79.1 & 6.3 & 0.05 \\
\hline Methomyl & 94.1 & 5.87 & 111.1 & 11.51 & 109.1 & 7.7 & 114.7 & 9.6 & 0.05 \\
\hline Isoprocarb & 93.2 & 5.80 & 79.9 & 11.02 & 112.9 & 9.0 & 83.5 & 4.6 & 0.03 \\
\hline Propuxur & 96.3 & 3.44 & 88.8 & 8.90 & 123.2 & 10.2 & 89.1 & 3.9 & 0.02 \\
\hline BPMC & 91.3 & 3.31 & 70.0 & 12.09 & 106.5 & 6.1 & 91.6 & 5.8 & 0.02 \\
\hline Carbofuran & 85.2 & 5.26 & 87.8 & 11.51 & 120.4 & 6.8 & 80.7 & 6.2 & 0.05 \\
\hline Pirimicarb & 90.2 & 5.99 & 84.9 & 6.60 & 116.8 & 4.5 & 83.4 & 10.8 & 0.02 \\
\hline 3-OH carbofuran & 80.4 & 6.81 & 103.3 & 2.02 & 124.6 & 11.7 & 100.3 & 3.9 & 0.1 \\
\hline$\beta$-Cypermethrin & 91.8 & 15.46 & 98.1 & 19.55 & 95.6 & 5.8 & 87.9 & 15.0 & 0.1 \\
\hline Fenvalerate & 94.9 & 13.02 & 81.9 & 18.40 & 100.2 & 15.0 & 92.6 & 12.9 & 0.1 \\
\hline Deltamethrin & 81.3 & 12.25 & 76.5 & 6.11 & 85.9 & 4.7 & 77.4 & 8.5 & 0.1 \\
\hline
\end{tabular}

cucumber, cabbage, cole and capsicum, which were purchased from supermarket in Beijing.

A Varian ion trap Saturn 2100 with MSn-option and multi CI-option was coupled with a Varian 3800 gas chromatograph. DB-5 ms capillary column of $30 \mathrm{~m}$, $0.25 \mathrm{~mm}$ I.D. and $0.25 \mu \mathrm{m}$ film thickness was employed through the studies. MS transfer line temperature $280^{\circ} \mathrm{C}$, ion trap temperature $200^{\circ} \mathrm{C}$. Carrier gas $(\mathrm{He})$ at the constant flow rate of $1 \mathrm{~mL} \mathrm{~min}{ }^{-1}$. The temperature program of the injector was held at $80^{\circ} \mathrm{C}$ for $1 \mathrm{~min}$, then raised to $150^{\circ} \mathrm{C}$ at the rate of $10^{\circ} \mathrm{C} \mathrm{min}^{-1}$, then to $220^{\circ} \mathrm{C}$ at $30^{\circ} \mathrm{C} \mathrm{min}{ }^{-1}$, to $280^{\circ} \mathrm{C}$ at $40^{\circ} \mathrm{C} \mathrm{min}{ }^{-1}$, with the final hold time of $10 \mathrm{~min}$. The ion trap was operated in full scan mode detection ions between $50 \mathrm{~m} / \mathrm{z}$ and $650 \mathrm{~m} / \mathrm{z}$.

Stock solutions $\left(1 \mathrm{mg} \mathrm{mL}^{-1}\right)$ of each pesticide standard were prepared by dissolving $0.1 \mathrm{~g}$ of the pesticide in 
$100 \mathrm{~mL}$ methanol. Work solution was prepared from the stock solution by serial dilutions. Stock standard and working solutions were stored at $4^{\circ} \mathrm{C}$.

A $50 \mathrm{~g}$ aliquot of chopped and homogenized sample was weighed in a $250-\mathrm{mL}$ polypropylene container; sodium chloride $(15 \mathrm{~g})$, acetone $(200 \mathrm{~mL})$ and dichloromethane $(150 \mathrm{~mL})$ were added. The mixture was vigorously shaken for $40 \mathrm{~min}$, and filtered through a 12-cm Büchner funnel; the solid residues were treated with an additional acetone $(30 \mathrm{~mL})$ and dichloromethane $(30 \mathrm{~mL})$. The filtrate was transferred into a $500-\mathrm{mL}$ separatory funnel, and the phase was allowed to separate by salting out process. The lower aqueous layer was discarded. Anhydrous sodium sulfate $(10 \mathrm{~g})$ was added to the separatory funnel and the funnel was shaken for $30 \mathrm{~s}$ in order to remove the residual water. The dried extract was filtered through coarse filter paper, and evaporated at $45^{\circ} \mathrm{C}$ to dryness on the rotary evaporator. The residue obtained was dissolved in the mixture of acetone and ethyl acetate $(5 \mathrm{~mL}, \mathrm{v} / \mathrm{v}, 1 / 1)$, and $2 \mathrm{~mL}$ for further cleanup. Extraction purification was performed employing cartridges $(6 \mathrm{~mL})$ filled with $500 \mathrm{mg}$ different sorbents (florisil, GCB, silicon dioxide, or GCB in combination with acidic aluminum oxide). Anhydrous sodium sulfate (ca. $2 \mathrm{~cm}$ layer) was always added to top of the cartridges, and the cartridges were preconditioned with $n$-hexane $(2 \mathrm{~mL})$. The cartridges were loaded with acetone/ethyl acetate extraction $(2 \mathrm{~mL})$. This eluate $(2 \mathrm{~mL})$ was discarded. Analytes were eluted with acetone/ethyl acetate $(30 \mathrm{~mL}, 1 / 1, \mathrm{v} / \mathrm{v})$ and concentrated in a rotary evaporator $\left(40^{\circ} \mathrm{C}\right)$ and completely dried under a nitrogen purge. The residues were re-constituted in ethyl acetate $(1 \mathrm{~mL})$ for GC IT/MS analysis.

Untreated vegetable samples $(50 \mathrm{~g})$ were fortified with known amounts of each pesticide at three levels $(0.1,0.5$ and $2.0 \mathrm{mg} / \mathrm{kg}$ ) and processed according to the above procedure. Every recovery was done on three replicates.

\section{Results and Discussion}

The described method comprised an extraction of the residual pesticides in vegetables with the mixture of acetone and dichloromethane considering the polarity of 39 pesticides and solubility ranges of the different pesticide families in organic solvent. Water and water-solubility impurity were removed from the raw extract by salting out with sodium chloride. As next step, the crude extract is clean-up by SPE cartridges. Among the solid-phase materials tested were florisil, GCB, and GCB in combination with acidic aluminum oxide, and the best results were obtained using GCB in combination with acidic aluminum oxide. Clean up on this SPE cartridge eliminated most interfering peaks and allowed good recoveries at low fortification levels.
For the identification of the target compounds, we tested the 39 pesticides based on the calibration standard at $0.1 \mathrm{mg} / \mathrm{kg}$. The results of threefold measurement and all chromatographic and mass spectral data are shown in Table 1.

The GC-MS response for 39 pesticides was linear in the concentration assayed $(0.05-2.0 \mathrm{mg} / \mathrm{kg})$ with determination coefficients $>0.996$ for all pesticides tested. Quantification was based on the abundance of each ion monitored by GC-MS.

Four uncontaminated vegetable samples (cucumber, cabbage, cole and capsicum) were spiked with known amounts of each pesticide $(0.1,0.5$ and $2.0 \mathrm{mg} / \mathrm{kg})$ and processed as described. Average recovery data and variation coefficients $(\mathrm{CV})$ obtained are shown in Table 2. Recoveries of $>90 \%$ of the pesticides were between $70 \%$ and $110 \%$, whereas triasophos gave very poor recoveries of $<50 \%$. The limit of detection (LOD) was determined as the lowest concentration giving a response of 3 times the average of the baseline noise from four non-fortified samples. In this study, LODs for all compounds range between 0.02 and $0.1 \mathrm{mg} / \mathrm{kg}$.

A simple, rapid and sensitive analytical method for the simultaneous determination of 39 pesticides in four vegetables has been developed. As a result of this study the procedure has been successfully applied in our laboratory for the routine screening of vegetable samples. In addition to removing the use of chlorinated solvents and reducing the volumes of solvents required in general, the SPE procedure allowed increased sample throughput compared with liquid-liquid extraction procedures. Gas chromatography with ion trap mass spectrometer has provided a good way for qualitative and quantitative utility and sensitivity.

Acknowledgment This work was supported by the financial support of National Natural Science Foundation of China (No. 20777078).

\section{References}

Albero B, Sánchez-Brunete C, Tadeo JL (2004) Analysis of pesticides in honey by solid-phase extraction and gas chromatographymass spectrometry. J Agric Food Chem 52:5828-5835. doi: 10.1021/jf049470t

Albero B, Sánchez-Brunete C, Tadeo JL (2005) Multiresidue determination of pesticides in juice by solid-phase extraction and gas chromatography-mass spectrometry. Talanta 66:917924. doi:10.1016/j.talanta.2004.12.046

Fenoll J, Hellín P, Martínez CM, Miguel M, Flores P (2007) Multiresidue method for analysis of pesticides in pepper and tomato by gas chromatography with nitrogen-phosphorus detection. Food Chem 105:711-719. doi:10.1016/j.foodchem.2006. 12.060

Fillion J, Hindle R, Ladroix M, Swlwyn J (1995) Multiresidue determination of pesticides in fruit and vegetables by gas chromatography-mass-selective detection and liquid chromatography with fluorescence detection. J AOAC Int 78:1252-1266 
Fillion J, Sauvé F, Selwyn J (2000) Multiresidue method for the determination of residues of 251 pesticides in fruits and vegetables by gas chromatography/mass spectrometry and liquid chromatography with fluorescence detection. J AOAC Int 83: 698-713

Lee SM, Papathakis ML, Feng HMC, Hunter GF, Carr JE (1991) Multipesticide residue method for fruits and vegetables:
California Department of Food and Agriculture. Fresenius' J Anal Chem 339:376-383. doi:10.1007/BF00322352

Liao W, Joe T, Cusick WG (1991) Multiresidue screening method for fresh fruits and vegetables with gas chromatographic/mass spectrometric detection. J AOAC Int 74:554-565 